\title{
Unfinished first-line tuberculosis treatment in primary care in Indonesia
}

\author{
AL ASYARY1, 2, A-F, YODI MAHENDRADHATA 3 , A, E \\ ORCID ID: 0000-0003-2150-0429 ORCID ID: 0000-0002-4522-1785 \\ ${ }^{1}$ Department of Environmental Health, Faculty of Public Health, Universitas Indonesia, Depok, Indonesia \\ ${ }^{2}$ Center of Educational and Community Services (P3M), Faculty of Public Health, Universitas Indonesia, Depok, \\ Indonesia \\ ${ }^{3}$ Department of Health Policy and Management, Faculty of Medicine, Public Health, and Nursing, \\ Universitas Gadjah Mada, Yogyakarta, Indonesia
}

A - Study Design, B - Data Collection, C - Statistical Analysis, D - Data Interpretation, E - Manuscript Preparation, F - Literature Search, G - Funds Collection

Summary Background. Unfinished tuberculosis (TB) treatment has slowly but surely become an unexpected event in the disease's development into drug-resistant TB. Developing countries, mostly comprised of Asian and Eastern European countries, including Indonesia, have been overwhelmed in preventing drug-resistant TB outcomes and have also failed to avoid the development of this disease. Objectives. This review discusses the current issue of an unfinished first-line TB treatment strategy in primary care in Indonesia, presenting some relevant strategies in developing countries.

Material and methods. A narrative review approach conducted on all existing evidence in selected scientific bibliographic sources. The researchers defined the keywords based on the research question as a search strategy.

Results. Scarce resources and limited access, alongside national policy on TB control and management, contribute in different ways to impede first-line TB treatment in Indonesia. Empowerment of TB patients and their families are considered the best ways to increase awareness on TB medication in a low- to middle-income setting. The role of the hospital and private practitioner networks in the treatment and management of TB patients is essential for developing active-case-finding-approach programs for TB suspects in primary care in an Indonesian setting. Contrarily, the potential misunderstandings in TB treatment have led to peculiar events affected by poor surveillance systems for TB investigation contacts to prevent TB incidences in large populations.

Conclusions. This study addressed the barrier of all stakeholders, particularly primary care, to achieve the Indonesian government's goals of TB elimination by 2030 and zero TB findings by 2050.

Key words: tuberculosis, drug resistance, Indonesia, developing countries, primary care.

Asyary A, Mahendradhata Y. Unfinished first-line tuberculosis treatment in primary care in Indonesia. Fam Med Prim Care Rev 2019; 21(2): 185-188, doi: https://doi.org/10.5114/fmpcr.2019.84556.

\section{Background}

\section{Rationale}

Multidrug-resistant tuberculosis (MDR-TB) has become a global social health problem, in which the disease is immune to first-line drugs, such as isoniazid and/or rifampicin [1]. MDR-TB has affected more developing countries than developed ones [2-4].

Unfinished first-line TB treatment has emerged as a large proportion of MDR-TB incidences, consisting of failure, default and relapse of TB treatment $[3,5]$. Management of TB therapy on non-directly observed treatments (DOTs) at health facilities $[3,6]$, the lack of a gold standard of drug-susceptibility facilities for diagnosis $[7,8]$ and poor TB patient access to medication $[5,8-10]$ are the main determinant factors for MDR-TB control, which is more complex in an under-resourced country setting.

Several developing countries have been encouraging their central governments' activities and programs through the primary care policy related to this agenda [11], including any necessary efforts to prevent TB, such as bacille Calmette-Guerin (BCG) vaccination, which is still disputed [12]. Indonesia, which ranks $9^{\text {th }}$ out of 27 countries in high-burden MDR-TB diseases
[1], focused on this strategy by committing to a local government policy in four provinces in 2012. Previously, drug-resistant TB surveys began in 2006 in the Jawa Tengah Province, as the national TB policy resulting from the estimation of MDR-TB reached $1.8 \%$ of TB incidence and $17.1 \%$ of TB default [13]. Based on the National Action Plan on Programmatic Management of Drug Resistance Tuberculosis (RAN-PMDT), TB-drug resistance in Indonesia has been affected by (1) poor quality of implementation of DOTs in hospitals and any other health facilities except health centers, (2) increase in TB-HIV coinfection, (3) poor surveillance system, and (4) the lack of TB case management for TB-drug resistance facilities [14].

\section{Objectives}

This study aims to explore a developing country's strategy of unfinished first-line TB treatment in primary care. This narrative review particularly examines TB control and management in the Indonesian setting.

We examined recent literature on the current issue and prospects for the unfinished treatment of TB, with MDR-TB as a common outcome for treatment failure resulting from the government policy associated with adherence to TB therapy in numerous studies. 


\section{Material and methods}

\section{Eligibility criteria}

We assemble all existing evidence relevant to TB mitigation and control in primary care in Indonesia to identify evidence gaps, all forms of literature, including published or unpublished scientific articles or government/institution reports, and other related eligible documents for review in Bahasa Indonesia or English. No publication date or publication status restrictions were imposed.

\section{Evidence resources}

In this review, we researched bibliographic sources, i.e. MEDLINE, EMBASE, CINAHL, Cochrane Library, Science Direct, ProQuest, WHO SEARO database, SCOPUS, Wiley Library, SAGE, Taylor \& Francis, SpringerLink, Hindawi and Directory of Open Access Journals (DOAJ). We also researched literature not listed in the above bibliographic resources using the Indonesian Portal Indexing (IPI), and we examined recent literature on the current issue and prospects for the unfinished treatment of TB, with MDR TB as a common outcome for treatment failure of TB resulting from the government policy associated with adherence to TB therapy in numerous studies.

\section{Search strategy}

Two researchers defined the keywords based on the research question. No years of publication and language restriction were placed on the search strategy. The team researcher used the keywords to conduct the search and input the search results into the Mendeley library. Subsequently, we assessed all meta-data for each article, including the abstract and full-text, and discuss it to the meeting.

\section{Results and discussion}

\section{Poor quality of implementation of DOTs in hospi- tals and in other health facilities}

Insufficient implementation of DOTs, either in hospitals, public lung clinics and private health practice, has led to inad- equate MDR-TB medication [15]. In 2007, assessment results of implementation of DOTs in 50 hospitals showed a default rate of TB patients reaching $10 \%$ to $20 \%$ of category 1 and $6 \%$ to $29 \%$ of category 2 (Table 1). Otherwise, the average success rate in the hospital was only at $60 \%$ out of the $85 \%$ national target, which is less for category 2 at $6.5 \%$. Therefore, more than $90 \%$ of TB patients experiencing default in the hospital had a high risk of MDR-TB [16].

The low success rate of TB treatment was also affected by a poor case holding process that led to a poor compliance rate of TB patient treatment. There was also a lack of family support and insufficient internal networking between hospitals and external networking between hospitals and other healthcare facilities that implemented DOTs (hospital DOT linkage). Indeed, the level of knowledge, attitude and patient behavior also contributed to poor compliance of TB treatment [17].

Other factors related to inadequate implementation of DOTs in hospitals included the use of non-standardized TB drugs. One study on prescriptions for TB treatment in hospitals found free TB drugs from DOT programs in only $13 \%$ of prescriptions; the rest referred to generic brands of TB drugs [19]. The results of a clinical audit in hospitals that have implemented DOT treatment before also showed an equal pattern of TB drug utilization that is practically non-standardized. Furthermore, inappropriate deficiency criteria for doses of TB drugs were found in $69 \%$ to $100 \%$ of 387 audited hospital medical records [20].

Otherwise, the TB drug group that is usually given alongside first-line TB drugs is quinolone, particularly ciprofloxacin, which is available commercially. This study on hospital prescriptions showed a general pattern of TB drug combination HRE or HRZE prescription alongside ciprofloxacin (11.6\% of category 1 regimen and $12.1 \%$ of category 2 regimen) or single-regimen ciprofloxacin ( $0.75 \%$ of category 1 and $7.9 \%$ of category 2$)$ [18].

Another threat that surfaced was the unrestricted sale of at least three second-line TB drugs that are freely available on the commercial market: fluoroquinolone, kanamycin and amikacin. These drugs are freely accessible and are the most utilized by healthcare facilities in both hospitals and private practice, without any standard term and regulation practices. Other second-line TB drugs, consisting of ethionamide, protionamide, PAS and cycloserin, proved ineffective, more expensive and harder to manage as a short-term package, with worse side effects. It is essential to prevent resistance to second-line TB drugs. Several studies have found that in countries where this disease was en-

\begin{tabular}{|c|c|c|c|c|c|c|c|c|c|c|c|c|}
\hline & \multicolumn{4}{|c|}{ Hospitals } & \multicolumn{4}{|c|}{ Lung Hospital } & \multicolumn{4}{|c|}{ Public Lung Health Clinics } \\
\hline & \multicolumn{2}{|c|}{2006} & \multicolumn{2}{|l|}{2007} & \multicolumn{2}{|c|}{2006} & \multicolumn{2}{|c|}{2007} & \multicolumn{2}{|c|}{2006} & \multicolumn{2}{|c|}{2007} \\
\hline \multirow{2}{*}{$\begin{array}{l}\text { No. of treated } \\
\text { TB cases }\end{array}$} & \multicolumn{2}{|c|}{1093} & \multicolumn{2}{|l|}{1694} & \multicolumn{2}{|l|}{451} & \multicolumn{2}{|l|}{266} & \multicolumn{2}{|l|}{269} & \multicolumn{2}{|l|}{167} \\
\hline & $n$ & $\%$ & $n$ & $\%$ & $n$ & $\%$ & $n$ & $\%$ & $n$ & $\%$ & $n$ & $\%$ \\
\hline Category 1 & 731 & 66.9 & 1169 & 69.0 & 271 & 60.1 & 201 & 75.6 & 246 & 91.4 & 161 & 96.4 \\
\hline Failure & 9 & 1.2 & 10 & 0.9 & 0 & 0.0 & 0 & 0.0 & 4 & 1.6 & 5 & 3.1 \\
\hline Default & 149 & 20.4 & 143 & 12.2 & 0 & 0.0 & 0 & 0.0 & 27 & 11.0 & 17 & 10.6 \\
\hline Treatment result unrecorded & 96 & 13.1 & 526 & 45.0 & 225 & 83.0 & 169 & 84.1 & 29 & 11.8 & 50 & 31.1 \\
\hline Category 2 & 29 & 66.9 & 11 & 69.0 & 28 & 60.1 & 16 & 75.6 & 17 & 91.4 & 3 & 96.4 \\
\hline Failure & 5 & 17.2 & 0 & 0.0 & 0 & 0.0 & 0 & 0.0 & 0 & 0.0 & 0 & 0.0 \\
\hline Default & 5 & 17.2 & 0 & 0.0 & 0 & 0.0 & 0 & 0.0 & 1 & 5.9 & 1 & 33.3 \\
\hline Treatment result unrecorded & 0 & 0.0 & 10 & 90.9 & 18 & 64.3 & 12 & 75.0 & 3 & 17.6 & 1 & 33.3 \\
\hline Relapse & 21 & 72.4 & 9 & 81.8 & 10 & 35.7 & 6 & 37.5 & 17 & 100.0 & 1 & 33.3 \\
\hline $\begin{array}{l}\text { Category } 1 \text { with smear positive } \\
\text { after intermittent phase }\end{array}$ & 13 & 1.2 & 7 & 0.4 & 1 & 0.2 & 1 & 0.4 & 11 & 4.1 & 10 & 6.0 \\
\hline
\end{tabular}


demic, the tuberculosis potentially developed as a genetic mutation of Mycobacterium tuberculosis sp. with a new variant of TB affecting either first-line and second-line TB drug resistance: TB Extra Drug Resistant (XDR) [17].

\section{Referral laboratory capacities for drug susceptibi- lity tests}

The laboratory capacity for MDR-TB is the essential component in facing the challenges of this disease from a diagnosis standpoint. Laboratory facilities have not been well developed or optimal, as the health system is still being strengthened in several under-resourced countries, including developing countries. The poor diagnosis system for MDR-TB is affected by the unavailability of a laboratory infrastructure, outdated laboratory guidelines and a quality assurance system fragmented by limited skilled laborers [21].

In Indonesia, only five laboratories are allowed to run drug susceptibility tests (DSTs), which have been certified by an international TB laboratory, the Institute of Medical and Veterinary Science (IMVS), Adelaide, Australia, which both diagnoses and leads the referral therapy for MDR-TB patients. These laboratories are the Microbiology Laboratory of the Faculty of Medicine, University of Indonesia; the Main Health Laboratory Clinic of Surabaya; the Microbiology Laboratory of Persahabatan Hospital; the Novartis Eijkmann Hasanuddin Clinical Research Initiatives (NEHCRI) Laboratory of the Faculty of Medicine, Hasanuddin University; and the Health Laboratory Clinic of Bandung. All these laboratories have undergone routine external quality assurance by IMVS for first-line and second-line TB drugs in the DST. The capacity of DST assessments is still low, i.e. less than 100,000 DSTs annually for all five laboratories. Their limited capacity was affected by running-out-of resources, either manpower or others [22].

\section{TB management strategy}

Patient-centered tuberculosis (PCT) is a promising strategy for TB medication [23]. It enables the patient to choose the treatment option or supervision model for drug consumption, whether in a healthcare facility under health professional supervision or at home with relatives who wish to supervise.

Options for treatment location, information related to medication and tuition from treatment supervisors should increase. Regular training is also needed for health workers to effectively supervise feasibility strengthening for a successful PCT approach.

Furthermore, PCT aims to gain access and compliance to TB treatment, as well as DOTs. TB patients, or their supervisors when they are unable to go to healthcare facilities, can procure the TB drugs every week in the incentive phase (within the first two months) and every two weeks in the advance phase (in the last four months). PCT eliminates the workload of health workers when they do not need to supervise the intake of TB drugs of their patients every day. It enables good quality of health professional care [23].

In conventional DOT approaches, TB patients are obligated to visit a healthcare facility every day for treatment. In many cases, this is hard for TB patients, as they are affected by their physical condition, distance from the facility and lack of either transportation or accommodation funds [24, 25]. Health workers, with an exceeded workload, tend to care for patients with unaffordable service. Meanwhile, it potentially decreases treatment adherence, since patients should be coming in every day [23].

Unfortunately, the PCT strategy lets patients identify passively. The period between realizing the symptoms and visiting healthcare facilities is missed. Therefore, access to healthcare is not affected by this approach. However, PCT enables health workers to consider newly diagnosed TB patients as TB incidences. Health workers also do not need to worry about being overwhelmed, which could happen when they serve all their TB patients. PCT supports the increase of access to diagnosis and the required medication indirectly, as it contributes to improving diagnostic procedures and assessments. The key to a PCT strategy lies in the option of a treatment location and supervision. Empowerment of TB patients and their families is essential to cover treatment care, which influences their compliance positively [26]. Prompt diagnosis and treatment leads to compliance and adequate medication based on effective TB control [23].

\section{Limitations of the study and future research}

This narrative review presents the current strategy of the Indonesian government in controlling first-line TB treatment as part of their national priority and strategy. The narrative review is not truly useful as scientific evidence, but it would be evidence-based [27]. This study was unable to clear the bias that caused the absence of systematic selection criteria, but it provides an evidence-based view of the current situation of unfinished TB treatment in developing countries. Thus, further studies are needed to set a more systematic approach to this issue, as well as its potential for MDR-TB disease development in developing countries.

\section{Conclusions}

The role of hospitals and private practitioner linkages in the treatment management of TB patients is critically required. It would be too late if TB control and management begins treatment only after the disease has developed into MDR-TB, particularly in under-resourced countries such as Indonesia. Healthcare facilities, which are not supported by the TB control strategy, tend to ignore the International Standard TB Care (ISTC) as its standard procedure for TB control. Poor accessibility by TB patients directly causes unfinished TB treatment. Further study is necessary to describe and analyze the pattern of unfinished TB patients, which is related to the potential of TB to develop into MDR-TB in developing countries.

Acknowledgments. This review is supported by the Corporate Social Responsibility of Aneka Tambang (CSR ANTAM) Co. Ltd. Scholarships Grant 2012 (grant No. 5/2012). We would also like to thank the contributors: Prof. Dr. Purwantyastuti, MD, MSc., Prof. Purnawan Junadi, MD, MPH, PhD. and Dr. Tris Eryando, MA.

Source of funding: This review is supported by the Corporate Social Responsibility of Aneka Tambang (CSR ANTAM) Co. Ltd. Scholarships Grant 2012 (grant No. 5/2012).

Conflicts of interest: The authors declare no conflicts of interest.

\section{References}

1. World Health Organization. Global Tuberculosis Control 2011. Geneva: WHO; 2011: 38.

2. He GX, Wang HY, Borgdorff MW, et al. Multidrug-resistant tuberculosis, people's Republic of China, 2007-2009. Emerg Infect Dis 2011; 17(10): 1831-1838.

3. Porwal C, Kaushik A, Makkar N, et al. Incidence and risk factors for extensively drug-resistant tuberculosis in Delhi Region. PLoS ONE 2013; 8: e5529, doi: https://doi.org/10.1371/journal.pone.0055299. 
4. Terlikbayeva A, Hermosilla S, Galea S, et al. Tuberculosis in Kazakhstan: an analysis of risk determinants in national surveillance data. BMC Infec Dis 2012; 12: 1-9, doi: 10.1186/1471-2334-12-262.

5. Nagaraja SB, Satyanarayana S, Chadha SS, et al. How do patients who fail first-line tb treatment but who are not placed on an MDR-TB Regimen Fare in South India. PLOS ONE 2011; 6(10): e25698, doi: 10.1371/journal.pone.0025698.

6. Wells WA, Ge CF, Patel N, et al. Size and usage patterns of private TB Drug Markets in the high burden countries. PLoS ONE 2011; 6(5): e18964, doi: 10.1371/journal.pone.0018964.

7. Lin H, Shin S, Blaya JA, et al. Assessing spatiotemporal patterns of multidrug-resistant and drug-sensitive tuberculosis in a South American setting. Epidemiol Infect 2011; 139: 1784-1793.

8. Park PH, Magut C, Gardner A, et al. Increasing access to the MDR-TB surveillance programme through a collaborative model in western Kenya. Trop Med Int Health 2012; 17(3): 374-379.

9. Brust JCM, Shah SN, Scott M, et al. Integrated, home-based treatment for MDR-TB and HIV in rural South Africa: an alternate model of care. Int J Tuberc Lung Dis 2012; 16: 998-1004.

10. Brust JCM, Gandhi NR, Carrara H, et al. High treatment failure and default rates for patients with MDR TB in KwaZulu-Natal, South Africa, 2000-2003. Int J Tuberc Lung Dis 2011; 14: 413-419.

11. Tyszko PZ, Nitsch-Osuch A, Mińko M, et al. Primary health care tasks in implementing the main operations of public health. Fam Med Prim Care Rev 2016; 18(3): 394-397.

12. Usman MM, Ismail S, Teoh TC. Vaccine research and development: tuberculosis as a global health threat. Cent Eur J Immunol 2017; 42(2): 196-204, doi: dx.doi.org/10.5114/ceji.2017.69362.

13. TB Indonesia. Multi-drug Resistant TB [Internet]. Directorate General for Disease Control and Environment Health, Indonesian Ministry of Health 2012 [cited 9.02.2015]. Available from URL: http://www.tbindonesia.or.id/tb-mdr/.

14. Ditjen-P2PL. Strategi Nasional Pengendalian TB Di Indonesia 2010-2014. Stop TB: Terobosan Menuju Akses Universal. Jakarta: Direktorat Jenderal Pengendalian Penyakit dan Penyehatan Lingkungan; 2011: 80.

15. Mahendradhata $\mathrm{Y}$, Utarini A, Lazuardi U, et al. Private practitioners and tuberculosis case detection in Jogjakarta, Indonesia: actual role and potential. Trop Med Int Health 2007; 12(10): 1218-1224.

16. Probandari A, Lindholm L, Stenlund $\mathrm{H}$, et al. Missed opportunity for standardized diagnosis and treatment among adult Tuberculosis patients in hospitals involved in public-private mix for directly observed treatment short-course strategy in Indonesia: a cross-sectional study. BMC Health Serv Res 2010; 10(113): 113, doi: 10.1186/1472-6963-10-113.

17. Ditjen-P2PL. Programmatic Management of Drug Resistance Tuberculosis Pengendalian Tuberkulosis. Rencana Aksi Nasional Indonesia 2010-2014. Jakarta, Indonesia: Kementerian Kesehatan Direktorat Jenderal Pengendalian Penyakit dan Penyehatan Lingkungan; 2011.

18. Utarini A, Probandari A, Lestari T, et al. Assessment of hospital DOTS implementation: component A. TB and HIV caseload in hospitals and clinics. Yogyakarta: Hospital Management Program, Postgraduate Program of Public Health, Faculty of Medicine - Universitas Gadjah Mada; 2007.

19. Utarini A, Probandari A, Lestari T, et al. Assessment of hospital DOTS implementation: component B. Implementation of DOTS hospital, TB-HIV collaboration and MDR-TB management. Yogyakarta: Hospital Management Program, Postgraduate Program of Public Health, Faculty of Medicine - Universitas Gadjah Mada; 2008.

20. Probandari A, Utarini A, Lindholm L, et al. Life of a partnership: the process of collaboration between the National Tuberculosis Program and the hospitals in Yogyakarta, Indonesia. Soc Sci Med 2011; 73(9): 1386-1394.

21. Paramasivan $\mathrm{CN}$, Lee $\mathrm{E}$, Kao $\mathrm{K}$, et al. Experience establishing tuberculosis laboratory capacity in a developing country setting. Int J Tuberc Lung Dis 2010; 14: 59-64.

22. P2PL D. Rencana Aksi Nasional Programmatic management of drug resistance tuberculosis pengendalian tuberkulosis Indonesia: 2011-2014. Jakarta: Kementerian Kesehatan Rl; 2011: 66.

23. Mkopi A, Range N, Amuri M, et al. Health workers ' performance in the implementation of Patient Centred Tuberculosis Treatment (PCT) strategy under programmatic conditions in Tanzania: a cross sectional study. BMC Health Serv Res 2013; 13: 101, doi: 10.1186/14726963-13-101.

24. Egwaga S, Range N, Lwilla F, et al. Assessment of patient preference in allocation and observation of anti-tuberculosis medication in three districts in Tanzania. Patient Prefer Adherence 2008; 2: 1-6.

25. Mahendradhata Y, Probandari A, Ahmad RA, et al. The incremental cost-effectiveness of engaging private practitioners to refer tuberculosis suspects to DOTS services in Jogjakarta, Indonesia. Am J Trop Med Hyg 2010; 82(6): 1131-1139.

26. Asyary A, Purwantyastuti, Eryando T, et al. Perceived of healthcare utilization by adult pulmonary tuberculosis patients for their children in Yogyakarta. Asian J Epidemiol 2017; 10(2): 70-75.

27. Pae C-U. Why systematic review rather than narrative review? Psychiatry Investig 2015; 12(3): 417-419.

Tables: 1

Figures: 0

References: 27

Received: 1.09 .2018

Reviewed: 15.09.2018

Accepted: 7.11.2018

Address for correspondence:

Dr Al Asyary

Department of Environmental Health

Faculty of Public Health

Universitas Indonesia

C Building 2nd Floor

Campus FKM-UI Depok Jawa Barat 16242

Indonesia

Tel./Fax: +6221-7863479

E-mail: al.asyary13@gmail.com, al.asyary@ui.ac.id 